\title{
Formação de Professores em Ambiente Digital: uma Experiência Interdisciplinar
}

\author{
Marcos Tarciso Masetto \\ Maria Elizabeth Bianconcini de Almeida \\ Myrtes Alonso \\ Ricardo Carvalho Rodrigues \\ Rosângela de Abreu Amadei Duarte
}

\section{Teacher Education in a Digital Environment: an Interdisciplinary Experience in a Graduate Course}


Resumo: O objetivo deste trabalho é apresentar a pesquisa realizada em 2003, no Programa de PósGraduação em Educação - Currículo da PUCSP, visando a construção e implementação de uma disciplina de pós-graduação totalmente a distância, procurando responder a alguns princípios assim formulados: realização de pesquisa interdisciplinar, produção científica, publicações, interação entre os participantes (interaprendizagem), participação em comunidades virtuais de aprendizagem, mediação pedagógica, produção individual e coletiva. Apresentamos o programa e o desenvolvimento da disciplina, a utilização das ferramentas da plataforma TelEduc, a estrutura dinâmica das pesquisas, debates e produções de documentos individuais e coletivos durante o decorrer da disciplina. Fazemos uma análise deste projeto exploratório, e indicamos algumas considerações finais. Por último, apresentamos também produções significativas de professores e alunos resultantes desta disciplina.

Palavras-chave: Formação de educadores. Educação a distância. Ambiente digital. Mediação. Interação. Interaprendizagem

Abstract: This paper concerns a research developed by a graduate education program (Programa de PósGraduação em Educação - Currículo PUC-SP), aiming at presenting the design and implementation of a distance learning course in the same program. The course involved interdisciplinary work, knowledge construction, publication, interaction among participants, participation in virtual communities, collective and individual production. We herein describe the program and development of the course, the use of the TelEduc platform tools, and the dynamic structure of the investigations carried out during the course. We provide an analysis of this exploratory project, along with some final considerations, pointing out a few of the most significant works created by the teachers and students involved with the course.

Keywords: Teacher education. Distance education. Digital environment. Mediation. Interaction. Learning community.

MASETTO, Marcos Tarciso et al. Formação de Professores em Ambiente Digital: uma experiência interdisciplinar. Informática na Educação: teoria \& prática, Porto Alegre, v.8, n. 2, p.45-54, jul./dez. 2005. 


\section{Introdução}

Os desafios contemporâneos para o desenvolvimento da educação a distância, aliados à necessidade de expansão dos cursos de Mestrado e Doutorado pelas diferentes regiões do país, e suas sérias dificuldades por exigir o deslocamento de professores doutores de sua sede para ministrarem cursos e orientarem dissertações e teses, levaram o Núcleo de Formação de Educadores do Programa de Educação: Currículo da PUCSP a realizar uma pesquisa-ação para a construção e implemento de uma disciplina no nível de pósgraduação "stricto sensu", a distância, respeitando alguns princípios educacionais:

- Educação a distância não se identifica com ensino a distância. A primeira está voltada para o desenvolvimento do aprendiz em seus vários aspectos: cognitivo, afetivo, de habilidades e de atitudes ou valores. O segundo se preocupa em transmitir informações e solicitar devoluções conteudísticas.

- Educação se constrói através do processo de aprendizagem e este se desenvolve com o envolvimento e desempenho individual do educando em parceria com os demais participantes do processo (colegas, professor, coordenador, tutor, monitor, e outros...). A interação e a interaprendizagem do grupo é fundamental para a construção do processo de aprendizagem.

- O papel do professor é o de mediador.

- Tecnologias integradas ao desenvolvimento dos projetos de formação de educadores, em ambientes digitais.

- Desenvolvimento de pesquisa sobre a temática da disciplina e produção científica dos participantes, uma vez que se trata de uma disciplina de pós-graduação "stricto sensu".

Com estes pressupostos, planejamos e realizamos uma pesquisa-ação com uma disciplina do Programa de Educação: Currículo do 2 ‥ Semestre de 2003.

\section{Desenvolvimento da Disciplina Investigada}

A disciplina ofertada se intitulou: "Formação de professores em ambientes digitais", com a participação de 19 alunos, 03 professores e 02 monitores.

Seus objetivos:

- produção de conhecimento pela pesquisa;

- formação pedagógica do docente do ensino superior, para desenvolver atividades com suporte em ambiente virtual;

- superação da fragmentação do conhecimento, trabalhando-se por integrar os conhecimentos de áreas diferentes numa perspectiva interdisciplinar;

- interação entre os elementos do grupo visando à formação de uma rede colaborativa (diálogo, estudos, leituras, levantamento de informações, debates, produção de textos individual e coletiva);

- uso da tecnologia digital para a produção de textos individual e em grupo;

- consulta às bases de dados científicos digitais;

- troca de informações com pesquisadores deste e de outros grupos;

- participação em grupos de discussão e em comunidades virtuais de aprendizagem. 


\section{$2.1 \quad$ Temática}

Análise de paradigmas e concepções educacionais subjacentes a projetos relevantes de formação de educadores em ambientes digitais, realizados em distintas instituições, bem como de metodologias e tecnologias integradas ao desenvolvimento dos projetos.

Os projetos foram analisados por meio de visitas virtuais e respectivas explorações de ambientes digitais de suporte às atividades, consulta a bases de dados científicos com possível debate com profissionais responsáveis. Para tanto, foi sugerida a consulta a autores que abordam temas referentes à EaD e formação de professores e que constituíram o aporte teórico que fundamentou esta proposta, tais como Ackermann, E. (2002), Alava, S. (org.). (2000), Almeida, F. J. eAlmeida, M. E. B. (2003), Almeida, M. E. B. (2003), Belloni, M. L. (1999), Litwin, E. (org.) (2001), Paloff, R. M. \& Pratt K. (2002), Sancho, Juana Maria. (org.) (2001), Silva, Marco (org.) (2003), Valente, J. A; Almeida, M. E. B. \& Prado, M. E. B. (2003).

\subsection{Metodologia}

Realizaram-se três encontros presenciais:

- o primeiro, no início do curso, para discussão com o grupo a respeito das expectativas dos participantes (alunos e professores) quanto à disciplina, seu programa, sua metodologia e seu processo de avaliação. Este plano foi publicado na íntegra na ferramenta Dinâmica do Curso, do TelEduc ${ }^{1}$, o que favoreceu o retorno contínuo a ele a fim de se situar a atividade em realização em relação à visão global da proposta.

Com o objetivo de tornar mais fácil o entendimento da proposta em sua totalidade, foi elaborado um quadro-síntese contendo as diferentes etapas do trabalho, os encaminhamentos das atividades correspondentes, os resultados/produtos esperados e o tempo destinado a cada uma das etapas, conforme especificado no quadro a seguir.

- o segundo, após a realização parcial da disciplina, com objetivo de avaliação do processo, tanto de aprendizagem como de pesquisa;

- o terceiro, ao final da disciplina, para uma avaliação geral do curso.

No desenvolvimento da disciplina foi utilizada como suporte às interações a plataforma TelEduc ${ }^{1}$, em virtude de suas características especiais relativas às possibilidades de vivências de interação, mediação e produção colaborativa de conhecimento. Esta ferramenta dispõe das seguintes ferramentas: agenda, mural, atividades, material de apoio, chat, fórum de discussão, portfólio individual e de grupo, além daquelas necessárias à administração da plataforma e da disciplina.

Os alunos produziram relatórios de visitas a cursos a distância, identificados na Internet, realizaram e comentaram entrevistas e produziram artigos, gerando material de referência para posterior publicação. Os conteúdos e as produções foram desenvolvidos nas interações virtuais e disponibilizados pelos alunos nos portfólios individuais ou dos grupos, conforme a natureza de sua criação.

\subsection{Processo de avaliação}

O processo avaliativo se constituiu de um feedback contínuo com relação às atividades, às inserções no TelEduc, participação em 
fóruns, em chats, com comentários aos textos produzidos e colocados nos porfólios individuais ou grupais. Tais feedbacks eram dados aos participantes pelos professores, pelos monitores e pelos próprios alunos, dependendo da situação.

\subsubsection{Unidades de trabalho}

Três foram as unidades de trabalho desenvolvidas nesta disciplina:

- Levantamento de cursos de formação de professores a distância encontrados na Internet.

- Pesquisas de temas conceituais relevantes identificados no levantamento da primeira unidade, para pesquisa em pequenos grupos, e produção coletiva de documentos.

- Avaliação dos produtos grupais, e produção de artigos individuais.

As três unidades de trabalho foram cumpridas conforme programado e registrado no TelEduc, no qual foram publicadas dez (10) agendas, que anunciavam as atividades a realizar no período.

Estas eram detalhadas na ferramenta Atividades do TelEduc, para que o aluno pudesse compreender as orientações sem incorrer no excesso de informações na tela de abertura do curso (agenda).

Foram usadas também as ferramentas, Material de Apoio e Leituras, conforme a finalidade do Material. Havia a preocupação em não criar amarras ao aluno com excesso de regras e roteiros lineares de trabalho, ao tempo que se cuidava para que não se sentisse perdido e desorientado pela falta de informações.

Cada Atividade trazia subsídios para a seguinte, criando um movimento em espiral que permitiu a aprendizagem pela pesquisa e o estabelecimento de articulação entre teoria e prática, tendo em vista os conhecimentos e experiências prévias dos alunos. Assim, a atividade publicada em 21.08.2003, propôs um cenário que levava em conta as experiências de EaD, que o aluno teve a oportunidade de conhecer nas publicações comentadas do evento da Sociedade Brasileira de Computação - SBC, ocorrido de 01 a 04.08.2003, e dos dados levantados sobre cursos existentes na Internet.

Para discussão temática, abriram-se fóruns que por vezes envolviam o coletivo da turma, noutros momentos pequenos grupos, permitindo o debate entre os componentes de cada grupo. Foram realizados 25 fóruns temáticos, sendo 18 coletivos dos quais participou a turma toda e 07 em grupos de trabalhos específicos.

Uma vez que um dos objetivos da disciplina era favorecer o desenvolvimento de um trabalho colaborativo entre os participantes, deslocando o centro do processo de ensino do professor para o grupo de aprendizagem, interessava aos pesquisadores saber em que medida a disciplina estaria propiciando a interação entre os participantes. Para isto servimo-nos da ferramenta Intermap, disponível no TelEduc, a qual disponibiliza o mapa de interações ocorridas em cada ferramenta, apresentando-o no formato de gráfico ou tabela em períodos definidos na consulta.

\subsubsection{Fórum: Congresso da SBC (Primeiro fórum)}

Um ponto que merece destaque no desenvolvimento da disciplina diz respeito à metodologia que, embora pautada por princípios já conhecidos e amplamente utilizados, apresenta aspectos inovadores que devem ser analisados. 
A preocupação, presente em várias disciplinas do Núcleo de Currículo e Formação, pertencentes ao programa de Pós-Graduação em Educação: Currículo, de trabalhar com dados da realidade e da experiência dos estudantes se apresentou, neste caso, da maior relevância para permitir a "ousadia" em termos de pesquisa, buscando idéias novas mesmo quando não consolidadas pela literatura. $O$ fato de não termos partido da teoria para a prática, em busca de possíveis aplicações de modelos existentes, mostrou-se essencial para libertar os estudantes das "amarras teóricas", exercendo uma atividade intensa de investigação ainda que em caráter exploratório, que permitiu o afloramento de dados e informações nem sempre visíveis sob a ótica da interpretação literária.

Essa "coragem" foi estimulada pela mediação dos formadores que, ao invés de definirem o caminho e apontarem as respostas, sugeriam novos modos de encaminhar a busca, ofereciam referências que poderiam auxiliar a pesquisa e encorajavam o avanço em novas direções.

Fundamental para esta atitude dos formadores foi o fato destes formadores constituírem uma equipe de trabalho, que se utilizou constantemente do recurso on-line de comunicação (lista de discussão ou chat) para definir e concretizar as diversas etapas de trabalho, bem como avaliá-las, passando por várias fases de depuração até que se definisse a Agenda a ser publicada.

A agenda, portanto, era elaborada em conjunto pelos formadores, após avaliação cuidadosa do processo de desenvolvimento dos alunos, utilizando-se uma linguagem amigável, ao tempo que se buscava conquistar o aluno para a realização das atividades. A apresentação da Agenda era também objeto de atenção dos formadores, trazendo em várias ocasiões metáforas, imagens sugestivas que, associadas ao texto, procuravam estimular os alunos no sentido de prosseguirem na busca de soluções para os problemas enfrentados.

\section{Produções dos alunos}

Como se tratava de uma disciplina de pós-graduação, se teve um cuidado especial com as atividades de pesquisa e documentação de seus resultados em produção de textos individuais e coletivos.

Diversas foram as produções desenvolvidas pelos alunos ao longo da disciplina.

$\mathrm{Na}$ unidade 1, foram realizadas produções individuais sobre o roteiro de visita em cursos de formação de professores a distância, encontrados na Internet, disponibilizados nos portfólios individuais. Os alunos também procuraram alternativas de solução para um cenário proposto, que foram apresentadas em um fórum; debatidas entre alunos e formadores; e que produziram sínteses individuais dos cursos encontrados. No final da unidade, cada aluno levantou uma problemática relacionada à formação de educadores com suporte em ambiente digital que considerava relevante para investigação conceitual.

A unidade 2, iniciou-se com a publicação pelos formadores dos aspectos conceituais extraídos das inserções em fóruns e documentos dos portfólios, categorizados em sete temas, dentre os quais um deles os alunos tiveram a oportunidade de selecionar para o desenvolvimento de uma pesquisa conceitual e respectiva produção (coletiva) de artigo, em pequenos grupos, formados pela congruência ou proximidade entre os temas selecionados. 
Os formadores se distribuíram para acompanhar e orientar as atividades de pesquisa dos pequenos grupos, de modo a instigar os alunos à investigação, a provocar reflexões, fornecer referências bibliográficas e outras informações que se evidenciassem como pertinentes ao desenvolvimento das pesquisas.

A atividade seguinte foi a auto-avaliação das produções grupais e, na atividade final, se retornou à produção individual para elaborar um artigo com tema extraído da pesquisa realizada em grupo. Para isso, os alunos deveriam utilizar como subsídios as leituras sugeridas ao longo do desenvolvimento da disciplina ou poderiam buscar outras leituras complementares. $\mathrm{O}$ essencial seria escolher as idéias de determinado autor como orientação para a linha de desenvolvimento do artigo, podendo inclusive realizar entrevistas com o autor escolhido ou com algum profissional da mesma linha de pensamento. A par dessa produção, iniciou-se um processo de reflexão sobre as vivências propiciadas pela disciplina no que se refere à pertinência ou não das condições criadas por esta disciplina para o desenvolvimento da aprendizagem colaborativa e paradigma emergente. Também se cuidou de orientar os alunos sobre a produção de um artigo científico, características principais e respectivas normas técnicas. Os artigos individuais produzidos foram depurados um a um com a orientação dos formadores e devolvidos aos alunos com orientações para sua re-elaboração.

\section{$4 \quad$ Avaliação dos pós-graduandos que participaram do projeto}

No último encontro presencial, foi desenvolvida uma Dinâmica para avaliação da disciplina, inicialmente com depoimentos livres dos alunos, nos quais se pode constatar a validade de um curso de pós-graduação "stricto sensu" a distância.

Um aspecto positivo bastante ressaltado pelos alunos refere-se à possibilidade de se criar situações de ensino que propiciem o desenvolvimento da autonomia para buscar informações, trabalhá-las e aprender de forma significativa; desenvolver referências que permitam aos alunos re-contextualizar as práticas em outras situações, utilizando a teoria de forma construtiva e renovadora.

Merece destaque o papel do formador que orienta, situa-se próximo ao aluno, mas deixa-o livre para fazer os próprios vôos. $O$ formador caminha junto do aluno, respeita seu movimento e compreende que não tem resposta para todas as questões e que todos são aprendizes.

Na seqüência, foi solicitado aos alunos que escrevessem frases para expressar suas opiniões sobre alguns tópicos que permitissem inferir o alcance dos objetivos do curso, conforme exemplos a seguir:

- Clareza de Orientações na Proposição de Atividades: A organização das orientações por agenda, estabelecendo prazos, orientando por tópicos, permitiu que os alunos se programassem por períodos relativamente curtos, criando um dinamismo envolvente.

- Temáticas trabalhadas na disciplina: As temáticas abordadas contemplaram aspectos nevrálgicos para a discussão acerca da "Formação de Professores em Ambientes Digitais".

- Ambiente e Ferramentas do TelEduc: O ambiente e as ferramentas do TelEduc facilitaram a atuação dos participantes e sua interação.

- Estratégias e Dinâmicas: As estratégias e dinâmicas diversificadas nos motivaram a 
participar e também buscar o melhor de nossas possibilidades.

\section{Considerações gerais}

Deste projeto exploratório, cabe ressaltar alguns aspectos que chamam a atenção e merecem ser levados em conta em atividades congêneres:

A interação entre os formadores foi intensa tanto em reuniões presenciais e a distância, como e, principalmente, por troca de mensagens em uma lista de discussão, cujos dados estão armazenados para análise.

A observação sistemática e a conseqüente análise da mediação nas diversas ferramentas se tornou possível graças à ação complementar dos monitores.

A descoberta da utilidade dos dados quantitativos das interações nas diversas ferramentas e de outros recursos tais como os gráficos demonstrativos das interações na ferramenta Intermap, para o melhor acompanhamento e orientação dos participantes.

A utilização de distintas linguagens foi fundamental para mobilizar os alunos a expressar sentimentos e percepções diante dos desafios propostos, merecendo ser melhor investigada para expandir tal uso em outros cursos.

Alguns problemas constatados merecem atenção especial em outras iniciativas:

- Uma das tarefas mais difíceis e que demandou maiores cuidados por parte dos formadores foi orientar os alunos para a produção de textos. É preciso considerar que a escrita do texto, dentro de critérios científicos é um processo que requer amadurecimento e assistência próxima do formador. Ela se torna ainda mais complexa quando supõe a utilização de subsídios teóricos e práticos elaborados a distância em cooperação com outros colegas. Seria ingênuo imaginar que as dificuldades apresentadas em cursos presenciais fossem minimizadas em curso desenvolvido a distância, sobretudo no prazo de um semestre letivo, em uma única disciplina.

- A carga horária dos professores e monitores dedicada às atividades desta disciplina foi bem maior do que a dispensada para um curso presencial, o que sugere a necessidade de uma equipe de trabalho com um número de horas superior ao habitualmente necessário para cursos presenciais. As formas de especificar contratos e dedicação usuais não são adequadas à docência em meio virtual.

- Como dissemos, houve um encontro presencial na metade do curso a distância. Neste momento persistiu a dificuldade já observada em outras atividades de retomar a interação à distância após o encontro presencial. Recomenda-se buscar outras estratégias para engatar o encontro presencial com as atividades virtuais que o seguem, de modo a evitar um espaço vazio de interações logo após esse encontro.

- Para que o curso seja apresentado aos alunos com um design agradável e integre diferentes linguagens às atividades, há necessidade do apoio de outros profissionais com as competências técnicas adequadas, tais como web designer, roteiristas, etc.

- Não conseguimos $100 \%$ de envolvimento e participação, uma vez que dois (2) dos 19 alunos não tiveram aproveitamento satisfatório na disciplina.

\section{Conclusões}

A intensa participação dos alunos no curso pode ter sido influenciada pela atenção especial dada pelos formadores aos seus interesses, a partir do levantamento dos tópicos abordados no curso, extraídos durante a fase 
inicial de interações, quando os alunos colocaram as suas demandas, permitindo a identificação dos seguintes itens como objeto de estudo em EaD: Avaliação, Auto-formação, Construção colaborativa do conhecimento, Design Educacional, Interação, Reflexão sobre a ação, Mediação Pedagógica.

Os temas listados foram objeto de estudo e investigação de grupos, que trabalharam por meio de interações no ambiente virtual, seja na busca de fontes bibliográficas, seja na exploração de sites e endereços eletrônicos, umas e outras sugeridas nos links criados para tal, pelos professores ou pelos próprios alunos.

Pode-se concluir que é possível realizar um curso de Mestrado "stricto sensu" a distância, uma vez que:

- O índice de permanência e participação foi muito bom: de todos os participantes, em número de 19, apenas 02 não realizaram todas as atividades e, por isso mesmo, foram convidados a refazer a disciplina em outra oportunidade;

- As produções dos alunos superaram a qualidade dos trabalhos normalmente entregues no final de disciplinas presenciais;

- Os alunos demonstraram, no decorrer das atividades, autonomia para a busca de informações significativas para os temas em estudo;

- As interações entre os alunos e entre alunos e professores foram viabilizadas durante todas as etapas do curso, evidenciando a superação da distância física com o "estar junto virtual", principalmente entre os alunos, o que indica a superação da relação hierárquica entre professor e alunos, e a constituição da interaprendizagem e parceria entre os participantes do processo de aprendizagem.

Os resultados destas pesquisas se transformaram em dissertações como esta já defendida "Mediação Pedagógica e chats educacionais: a tessitura entre colaborar, intermediar e co-mediar" de Valdenice Minatel Melo de Cerqueira; artigos individuais, como "Autonomia e construção colaborativa do conhecimento: a relação necessária a processos de auto-formação" de M. G. Franco, apresentado na XXIV Sociedade de Computação, na UFBA (2004) e classificado em primeiro lugar no Workshop de Informática da Escola-WIE do Congresso da SBC, em 2004. Outro artigo publicado na Revista Reflexão e Ação da Universidade de Sta. Cruz do Sul, com o título: "Refletindo os cursos de formação online à luz dos estudos sobre a interação, os valores e a linguagem emocional", de Maria Elizabeth Bianconcini deAlmeida, Adriana Rocha Bruno, Adriana Aparecida de Lima Terçariol e Ednilson Guiotti.

\section{Referências}

ACKERMANN, E. Ferramentas para um aprendizado construtivo: repensando a interação.

Disponível em <http://www.futurarte.com.br/artigos/eackermann1.htm> Acesso em: agosto de 2002.

ALAVA, S. (org.). Ciberespaço e formações abertas. Porto Alegre, RS: Artmed, 2000.

ALMEIDA, F. J.; ALMEIDA, M. E. B. Avaliação em meio digital: novos espaços e outros tempos de aprender ensinar e avaliar. Miami: VIRTUAL Educa, 2003.

ALMEIDA, M. E. B. Educação a distância: diretrizes políticas, práticas e concepções. In: Severino, J. J. e Fazenda, I. C. Políticas educacionais. $O$ ensino nacional em questão. Série Cidade Educativa. Vol. 3. São Paulo, SP: Papirus, 2003. 
Educação a distância na Internet: abordagens e contribuições dos ambientes digitais de aprendizagem. In: Educação e Pesquisa, v. 29 n. 2, pp. 327-339; SP:FEUSP, 2003.

BELLONI, M. L. Educação a Distância. Campinas, SP: Autores Associados, 1999.

LITWIN, E. (org.). Educação a Distância: Temas para o debate de uma nova agenda educativa.

Porto Alegre: Artes Médicas, 2001.

PALOFF, R. M.; PRATT, K. Construindo Comunidades de Aprendizagem no Ciberespaço:

Estratégias eficientes para salas de aula online. Porto Alegre: ArtMed, 2002.

SANCHO, J. M. (org.) Para uma tecnologia educacional. Porto Alegre: Artmed, 2001.

SILVA, M. (org.). Educação online: teorias, práticas, legislação, formação corporativa. São Paulo: Edições Loyola, 2003.

VALENTE, J. A; ALMEIDA, M. E. B. e PRADO, M. E. B. Formação de educadores via Internet. São Paulo: Avercamp, 2003.

Recebido em novembro de 2005

Aceito para publicação em dezembro de 2005

Marcos Tarciso Masetto

Professor Titular da PUCSP e da UPM.

E-mail:mmasetto@ajato.com.br

Maria Elizabeth Bianconcini de Almeida

Professora Associada da PUCSP.

E-mail:bbalmeida@uol.com.br

Myrtes Alonso

Professora Titular da PUCSP.

E-mail:myrtes@uol.com.br

Ricardo Carvalho Rodrigues

Doutorando do Programa de Educação: Currículo -

PUCSP

E-mail: rieli@rieli.com.br

Rosângela de Abreu Amadei Duarte

Doutoranda do Programa de Educação: Currículo -

PUCSP

E-mail: rosangelabreu@uol.com.br 